\title{
Do severity and duration of depressive symptoms predict cognitive decline in older persons? Results of the Longitudinal Aging Study Amsterdam
}

\author{
Hannie C. Comijs ${ }^{1}$, Theo van Tilburg ${ }^{2}$, Sandra W. Geerlings ${ }^{1}$, Cees Jonker ${ }^{1}$, Dorly J.H. Deeg ${ }^{1}$, \\ Willem van Tilburg ${ }^{1}$, and Aartjan T.F. Beekman ${ }^{1}$ \\ ${ }^{1}$ Department of Psychiatry, Institute for Research in Extramural Medicine (EMGO Institute), VU University \\ Medical Center, ${ }^{2}$ Department of Sociology and Social Gerontology, Vrije Universiteit, Amsterdam, The \\ Netherlands
}

ABSTRACT. Background and aims: Some prospective studies show that depression is a risk factor for cognitive decline. So far, the explanation for the background of this association has remained unclear. The present study investigated 1) whether depression is etiologically linked to cognitive decline; 2) whether depression and cognitive decline may be the consequence of the same underlying subcortical pathology, or 3) whether depression is a reaction to global cognitive deterioration. Methods: A cohort of 133 depressed and 144 non-depressed older persons was followed at eight successive observations over 3 years. All subjects were participants in the Longitudinal Aging Study Amsterdam (LASA). Depression symptoms were measured by means of the CES-D at eight successive waves. Cognitive function (memory function, information processing speed, global cognitive functioning) was assessed at baseline and at the last CES-D measurement. Results: The severity and duration of depressive symptoms were not associated with subsequent decline in memory functioning or global cognitive decline. There was an association between both chronic mild depression and chronic depression, and decline in speed of information processing. Conclusions: These results support the hypothesis that, in older persons, chronic depression as well as cognitive decline may be the consequence of the same underlying subcortical pathology.

(Aging Clin Exp Res 2004; 16: 226-232)

${ }^{\circ}$ 2004, Editrice Kurtis

\section{INTRODUCTION}

Prospective studies concerning the question whether late life depression is associated with subsequent cognitive decline have yielded conflicting results (1-8). However, there is sufficient evidence to assume that depression is a risk factor for cognitive decline (7). So far, the explanation for the background of this association has remained unclear.

The pathological effect of depression on cognitive function may be caused by high levels of glucocorticoids (cortisol). Secretion of glucocorticoids plays a central role in the short-term biological adaptation to stress. However, prolonged stress and prolonged exposure to hypersecretion of glucocorticoids may have adverse (neurotoxic) effects on the brain, particularly the hippocampus $(9,10)$, which plays a critical role in memory function, especially in the consolidation of short-term into long-term explicit memory, but also in the encoding of new information (11). Therefore, the severity and duration of depressive symptoms may lead to impairment of memory function.

There are two other explanations for the association between depression and cognitive decline. First, a common underlying organic pathology, for instance, in white matter and other subcortical abnormalities (12), may cause depression as well as cognitive decline in elderly respondents. Second, depression may be considered as a psychological reaction to eroding cognitive capacities early in the course of dementia (4).

In our former study (8), we investigated these three hypotheses on the association between late life depression

Key words: Cognition, cognitive decline, depression, older persons.

Correspondence: H.C. Comijs, PhD, LASA/EMGO, VU University Medical Center, Van der Boechorststraat 7, 1081 BT Amsterdam, The Netherlands.

E-mail: h.comijs@vumc.nl

Received March 28, 2003; accepted in revised form November 14, 2003. 
and cognitive decline, by examining whether depressive symptoms predict specific types of cognitive decline. We found that depressive symptoms were associated with a decline in speed of information processing, whereas there was no association between depression and increasing memory impairment or global mental deterioration. These results suggested that depressive symptoms are associated with motivational problems, as we see in subcortical pathology, and not with general cognitive decline or memory problems. However, as in most other prospective studies, depression was only measured twice, with a long interval between measurements (3 years). As depression often shows a variable course in time, exposure to depression may not have been accurately assessed for reliable measures of the severity and duration of depressive symptoms. Therefore, in the present study, depression symptoms were recorded at eight successive waves over a period of three years. At this moment, our study lacks measures of cortisol and brain imaging techniques, so that we were only able to evaluate the indirect effect of depression on cognitive performance.

The central research question in the present study is whether exposure to depressive symptoms is associated with decline in memory performance, greater than the general effect of aging. Furthermore, in order to replicate our former findings with these more detailed measures on depression, we also examined whether depression leads to a decline in information processing speed or global cognitive functioning.

\section{METHODS}

\section{Sample}

Data were derived from the Longitudinal Aging Study Amsterdam (LASA). LASA is a community-based study among persons aged 55 to 85 years in the Netherlands (13). A random sample, stratified for age and sex, was drawn from the population registries of 11 municipalities. This sample was first recruited for the NESTOR study on Living Arrangements and Social Networks of older adults (LSN), which had a response rate of $62.3 \%(\mathrm{~N}=3805)(14)$. About 11 months after the LSN interview, respondents were approached for the first LASA cycle, which forms the baseline for the current study. In total, 3107 subjects were enrolled in the baseline LASA interview, which took place between September 1992 and September1993 $\left(\mathrm{t}_{0}\right)$. All 3107 participants were screened for depression using the Center for Epidemiologic Studies-Depression scale (CES-D) (15). Due to item non-response on the CES-D, 51 subjects were lost, leaving a baseline sample of 3056 persons. All subjects scoring $\geq 16$ on the CES-D at baseline and a similarly sized random sample of those scoring $<16$ were approached for the follow-up study on depression. Response was $86 \%$ ( $\mathrm{N}=652$ : non-depressed cohort: $\mathrm{N}=325$, depressed cohort: $\mathrm{N}=327)$; non-response was related to age $(p<0.001)$ but not to gender $(16)$. Fol- low-up data were collected by mail questionnaires at 5month intervals in six successive waves, covering a period of 3 years. The final wave $\left(\mathrm{t}_{7}\right)$ consisted of the same faceto-face interview as the baseline interview.

As most cognitive tests were only performed by persons of 62 years and older, younger respondents were excluded from analyses $(\mathrm{N}=128)$. In order to study the longitudinal relation between depression and cognition, we included persons who completed the cognitive tests at $t_{0}$ and $t_{7}(\mathrm{~N}=106)$. The most important reason for loss to follow-up was death (47\%). Furthermore, persons were excluded when less than three follow-up measurements on depression were available $(\mathrm{N}=110)$, or when they had a history of stroke $(\mathrm{N}=31)$. The study sample consisted of 277 persons: 133 depressed and 144 non-depressed. Informed consent was obtained prior to the study, in accordance with legal requirements in the Netherlands.

\section{Measurements}

On all occasions $\left(t_{0^{-}} t_{7}\right)$, depressive symptoms were measured by means of the Center for Epidemiologic Studies-Depression scale (CES-D, 15). This self-report scale was developed to measure depressive symptoms in the community. It consists of 20 items in which respondents are asked how often they had experienced each symptom during the previous week. Each answer is rated on a 4-point scale ranging from 0 , 'rarely or never' to 3 , 'mostly or always'. The total scale score ranges from zero to 60 , in which higher scores indicate more depressive symptoms. A score of $\geq 16$ is generally accepted as indicative of clinically relevant depression symptoms (17). The scale has good psychometric properties in elderly samples. The criterion validity for major depression was very satisfactory (sensitivity $100 \%$, specificity $88 \%$ ) and the reliability was high (Cronbach's $\alpha=0.87$ ) (18).

Memory function was measured by means of a modified Dutch version of the Auditory Verbal Learning Test (AVLT, 19). This test consists of 15 words, which have to be learned during three trials. After every trial, respondents are asked to recall as many words as possible. After a distraction period of 20 minutes, they are asked to name the words they had learned before, again. The total number of words respondents reproduce during the three presentations is the immediate recall score, which ranges from 0-45. The number of words reproduced after 20 minutes is the delayed recall score, ranging from 0-15. The ratio of the maximum number of words on one of the trials at immediate recall and delayed recall is called the retention score. This reflects the percentage of words which respondents still remember according to the learning phase. Higher scores on the memory variables (immediate recall, delayed recall, and retention) indicate better memory performance. On $t_{0}$ and $t_{7}$, parallel versions of the AVLT were used in order to reduce practice effects. 
Information processing speed was measured by means of an adjusted version of the Coding Task (20). In this task, two rows of characters are shown, each character in the upper row belonging to a character in the lower row. The test contains also two rows, one containing characters and one empty. Respondents have to complete as many character-combinations as possible by naming the corresponding character. This was done in three cycles of one minute. The result of the best (fastest) trial is included in the present study.

General cognitive functioning was measured by means of the Mini-Mental State Examination (MMSE, 21), a frequently used screening instrument for global cognitive dysfunctioning. The scale consists of 23 items and scores range from $0-30$, higher scores indicating better cognitive functioning.

Change in cognitive performance between $t_{0}$ and $t_{7}$ was operationalized by means of difference scores by distracting $\mathrm{t}_{7}$-scores from $\mathrm{t}_{0}$-scores.

\section{Covariates}

Baseline sociodemographic variables included age and gender. The level of verbal intelligence was entered in the model as a covariate. Verbal intelligence is relatively insensitive to aging or mild cognitive impairment, and is therefore a more reliable measure of premorbid intelligence than level of education $(8,22)$. Verbal intelligence was measured by means of the GIT vocabulary test, a subtest of a Dutch intelligence test (Groninger Intelligentie Test, GIT), (23) during the second cycle of LASA $\left(\mathrm{t}_{7}\right)$. In this subtest, 20 words of increasing difficulty are presented, of which respondents have to choose synonyms out of five alternatives. The total score ranges between 0-20, higher scores reflecting higher levels of verbal intelligence.

The number of chronic diseases at both baseline $\left(\mathrm{t}_{0}\right)$ and last measurement $\left(\mathrm{t}_{7}\right)$ were included as covariates. The number of chronic diseases represented general physical health, associated with both depressive symptoms and cognitive functioning. The number of chronic diseases was determined by asking respondents if they suffered from the following chronic diseases: respiratory diseases, cardiovascular diseases, arteriosclerosis, diabetes mellitus, arthritis, or malignant neoplasms, and a maximum of two other diseases. Data were cross-checked with data supplied by general practitioners (24).

Alcohol intake was measured on the Garretsen scale (25), dichotomized into never/moderate drinking and heavy/excessive drinking. The latter was defined as drinking 4 or more glasses of alcohol during 5 or more days per week.

\section{Statistical analysis}

Exposure to depression was operationalized as the severity and duration of depressive symptoms. As a first step, for each individual with at least three follow-up measurements, linear regression was used to model the change in depressive symptom score (CES-D scores) over time (first- to fourth-order terms). On the basis of the obtained regression parameters, individual CES-D scores at seven points in time (at fixed intervals of half a year) were estimated. Baseline estimates and differences with the six subsequent estimates were the input for a cluster analysis to distinguish depression course types. Power calculations were carried out to determine if the sample size of the depression course types was sufficient to detect a clinically relevant difference of at least one standard deviation (SD) on the outcome variables, using an assumed power of $80 \%$ and a significance level of $5 \%$.

To examine the association between depression course types and cognitive decline, linear regression analyses were carried out. Change in cognitive functioning was computed by distracting the scores of $t_{7}$ from the baseline cognitive performance. In the first model, the association between change in cognitive functioning and depression course types were adjusted for the initial level of cognitive functioning, using the non-depressed group as reference. In the second model, the covariates were added to the model: age at $\mathrm{t}_{0}$, sex, verbal intelligence, number of chronic diseases at $t_{0}$ and $t_{1}$, and alcohol intake at $\mathrm{t}_{0}$ and $\mathrm{t}_{7}$.

\section{RESULTS}

According to the severity and duration of depressive symptoms, the best solution of the cluster analysis was to discriminate five distinct depression course types (Fig. 1). Cluster $1(\mathrm{~N}=37)$ were persons who were not depressed at baseline, but who reported increasing depressive symptoms

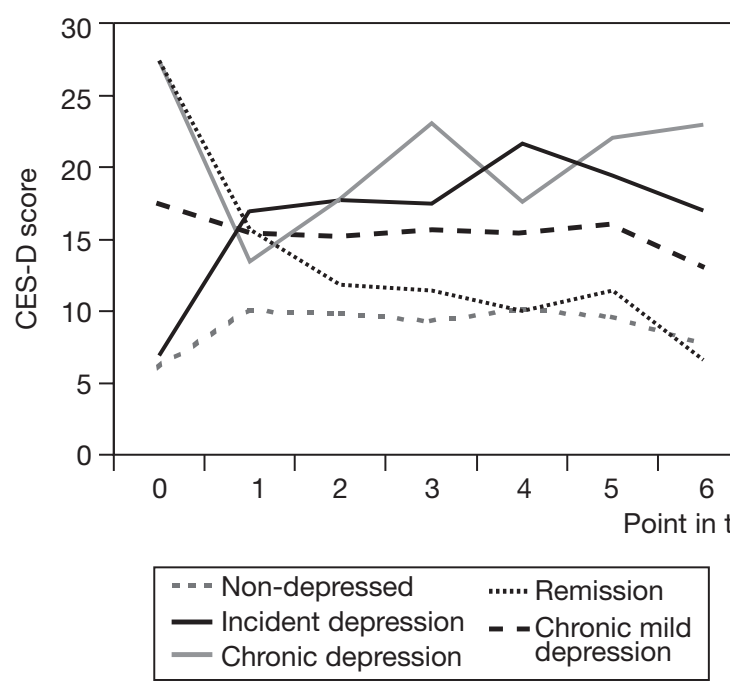

Figure 1 - Mean regression lines of five clusters of depression course types after cluster analysis. 
at follow-up (incident depression). Cluster $2(\mathrm{~N}=17)$ were persons who reported high levels of depressive symptoms at baseline, but who showed a remission during follow up (remission). Cluster 3 ( $\mathrm{N}=95$ ) was not depressed at baseline and remained so through the follow-up period (non-depressed). Cluster $4(\mathrm{~N}=103)$ reported mild depression throughout follow-up. This group will be referred to as chronic mild depression. Cluster $5(\mathrm{~N}=23) \mathrm{re}-$ ported fluctuating high levels of depressive symptoms throughout the follow-up period (chronic depression). In the cluster analysis, one cluster which consisted of only two persons with an extremely variable course of depressive symptoms, was systematically found (results not shown). Because of the small number $(\mathrm{N}=2)$, this cluster is not presented and was excluded from analyses.

Power calculations show that the minimum sample size required to detect a clinically relevant difference of at least one SD on the memory tests includes 11 persons for cluster 1 (incident depression), 10 persons for clusters 2 (remission) and 5 (chronic depression), and 17 for cluster 4 (chronic mild depression). As all course types contained at least 17 persons, the sample sizes were sufficient to determine significant clinical differences.
Table 1 presents the characteristics of the study sample according to course type. All depression course types consisted of more women than men, whereas in the non-depressed group the percentage of both sexes was about $50 \%$. The mean age was highest among chronic depressed persons (75 years). The mean CES-D score at baseline was lowest (7.5) for non-depressed persons, and highest (18.9) for chronic depressed persons.

Table 2 presents the results of regression analyses, in which the association between depression course type and change in cognitive performance was examined. In the first model, which examines whether depression course type is associated with change in cognitive performance, a significant association was found between cluster incident depression and change in immediate recall score on the memory test. Persons who became depressed during the follow-up had better scores on immediate recall. In the other depression course types, no such associations were found. No associations were found between depression course type and decline in memory performance, nor between depression course type and decline in global cognitive functioning (MMSE). Significant associations were found between chronic mild depression and chronic de-

Table 1 - Characteristics of sample according to depression course type.

\begin{tabular}{|c|c|c|c|c|c|}
\hline & $\begin{array}{c}\text { Non- } \\
\text { depressed } \\
\mathbf{N}=95\end{array}$ & $\begin{array}{c}\text { Incident } \\
\text { depression } \\
(\mathbf{N}=37)\end{array}$ & $\begin{array}{l}\text { Remission } \\
\qquad(\mathrm{N}=17)\end{array}$ & $\begin{array}{c}\text { Chronic mild } \\
\text { depression } \\
(\mathbf{N}=103)\end{array}$ & $\begin{array}{c}\text { Chronic } \\
\text { depression } \\
(\mathrm{N}=23)\end{array}$ \\
\hline Male / Female & $47 / 48$ & $14 / 23$ & $5 / 12$ & $33 / 70$ & $3 / 20$ \\
\hline Age at $t_{0}$, mean $(\mathrm{SD})$ & $72.3(6.5)$ & $71.9(6.0)$ & $73.0(7.1)$ & $72.8(6.5)$ & $75.0(7.4)$ \\
\hline Verbal intelligence, mean (SD) & $12.8(3.8)$ & $12.7(3.9)$ & $12.1(3.4)$ & $12.6(4.0)$ & $11.6(4.2)$ \\
\hline \multicolumn{6}{|l|}{ \# Chronic diseases } \\
\hline $\mathrm{t}_{0}$, mean $(\mathrm{SD})$ & $1.1(0.9)$ & $1.6(1.1)$ & $1.3(1.0)$ & $1.7(1.3)$ & $1.8(1.4)$ \\
\hline$t_{7}$, mean $(S D)$ & $1.5(1.2)$ & $1.7(1.0)$ & $1.5(1.1)$ & $2.1(1.3)$ & $2.2(1.5)$ \\
\hline \multicolumn{6}{|l|}{ Alcohol intake } \\
\hline - heavy / excessive at $t_{0}, \%$ & 1.1 & 2.7 & 0 & 3.9 & 0 \\
\hline - heavy / excessive at $t_{7}, \%$ & 1.1 & 5.4 & 0 & 4.9 & 0 \\
\hline CES-D, mean (SD) & $7.5(6.4)$ & $14.2(8.1)$ & $12.4(7.3)$ & $13.9(7.0)$ & $18.9(6.9)$ \\
\hline \multicolumn{6}{|l|}{ Immediate recall } \\
\hline $\mathrm{t}_{0}$, mean $(\mathrm{SD})$ & $19.3(5.7)$ & $18.4(5.9)$ & $18.6(5.6)$ & $18.6(5.5)$ & $17.9(7.4)$ \\
\hline$t_{7}$, mean $(S D)$ & $19.7(6.8)$ & $21.2(6.6)$ & $17.4(5.1)$ & $19.1(6.0)$ & $18.4(7.7)$ \\
\hline \multicolumn{6}{|l|}{ Delayed recall } \\
\hline $\mathrm{t}_{0}$, mean $(\mathrm{SD})$ & $5.1(2.7)$ & $5.7(3.0)$ & $5.0(2.6)$ & $5.2(2.6)$ & $5.0(2.7)$ \\
\hline $\mathrm{t}_{7}$, mean $(\mathrm{SD})$ & $5.9(3.1)$ & $6.6(3.1)$ & $5.3(2.4)$ & $5.8(3.1)$ & $5.6(3.6)$ \\
\hline \multicolumn{6}{|l|}{ Retention score } \\
\hline $\mathrm{t}_{0}$, mean $(\mathrm{SD})$ & $60.5(23.1)$ & $68.2(24.0)$ & $60.2(21.1)$ & $65.6(26.5)$ & $60.4(33.8)$ \\
\hline $\mathrm{t}_{7}$, mean $(\mathrm{SD})$ & $69.5(25.7)$ & $71.7(21.1)$ & $69.4(22.2)$ & $69.2(27.4)$ & $67.8(28.5)$ \\
\hline \multicolumn{6}{|l|}{ Information processing speed } \\
\hline $\mathrm{t}_{0}$, mean $(\mathrm{SD})$ & $26.6(7.4)$ & $25.9(6.7)$ & $25.9(5.5)$ & $26.1(7.0)$ & $24.7(7.4)$ \\
\hline$t_{7}$, mean $(S D)$ & $25.9(7.4)$ & $24.9(7.8)$ & $25.6(6.4)$ & $25.6(6.4)$ & $21.5(8.7)$ \\
\hline \multicolumn{6}{|l|}{ MMSE } \\
\hline $\mathrm{t}_{0}$, mean $(\mathrm{SD})$ & $27.7(1.9)$ & $26.7(2.7)$ & $27.2(2.4)$ & $27.3(2.0)$ & $26.3(2.8)$ \\
\hline $\mathrm{t}_{7}$, mean $(\mathrm{SD})$ & $27.3(2.3)$ & $26.8(3.0)$ & $26.8(2.5)$ & $27.1(2.3)$ & $26.1(3.6)$ \\
\hline
\end{tabular}


Table 2 - Linear regression analyses on association between depression course type and change in cognitive performance.

\begin{tabular}{|c|c|c|c|c|c|c|c|c|c|c|}
\hline & \multicolumn{2}{|c|}{$\begin{array}{l}\text { Immediate } \\
\text { recall }\end{array}$} & \multicolumn{2}{|c|}{$\begin{array}{l}\text { Delayed } \\
\text { recall }\end{array}$} & \multicolumn{2}{|c|}{ Retention } & \multicolumn{2}{|c|}{$\begin{array}{c}\text { Information } \\
\text { processing speed }\end{array}$} & \multicolumn{2}{|c|}{ MMSE } \\
\hline & Beta & $p$ & Beta & $p$ & Beta & $p$ & Beta & $p$ & Beta & $p$ \\
\hline \multicolumn{11}{|l|}{ Univariate $^{*}$} \\
\hline Incident depression & -0.22 & 0.01 & -0.04 & 0.67 & 0.01 & 0.91 & 0.08 & 0.36 & 0.02 & 0.84 \\
\hline Remission & 0.13 & 0.16 & 0.09 & 0.35 & 0.00 & 0.99 & -0.03 & 0.73 & 0.05 & 0.60 \\
\hline Chronic mild depression & 0.00 & 0.99 & 0.05 & 0.44 & 0.03 & 0.65 & 0.14 & 0.05 & -0.01 & 0.88 \\
\hline Chronic depression & -0.00 & 0.98 & 0.04 & 0.65 & 0.02 & 0.78 & 0.27 & 0.00 & 0.06 & 0.54 \\
\hline \multicolumn{11}{|l|}{ Multivariate $e^{* *}$} \\
\hline Incident depression & -0.19 & 0.02 & -0.06 & 0.49 & -0.01 & 0.93 & 0.09 & 0.34 & 0.05 & 0.54 \\
\hline Remission & 0.12 & 0.18 & 0.08 & 0.36 & 0.01 & 0.95 & 0.00 & 0.97 & 0.03 & 0.71 \\
\hline Chronic mild depression & -0.02 & 0.75 & 0.04 & 0.58 & 0.04 & 0.54 & 0.12 & 0.10 & 0.02 & 0.74 \\
\hline Chronic depression & -0.06 & 0.53 & -0.02 & 0.80 & -0.01 & 0.95 & 0.33 & 0.00 & 0.01 & 0.89 \\
\hline
\end{tabular}

"Linear regression analyses adjusted for level of cognitive functioning at baseline, with the non-depressed group as reference. **Linear regression analyses adjusted for age, sex, level of verbal intelligence, chronic diseases and alcohol, with the non-depressed group as reference.

pression, and a decline in information processing speed.

In the second model, the covariates age, sex, level of verbal intelligence, chronic diseases at $\mathrm{t}_{0}$ and $\mathrm{t}_{7}$, and alcohol use at $\mathrm{t}_{0}$ and $\mathrm{t}_{7}$ were added. This did not change the association between incident depression and immediate recall. The association between mild chronic depression and decline in information processing speed was no longer significant, whereas this association remained significant in chronic depression.

\section{DISCUSSION}

In later life, both depression and cognitive decline are highly prevalent, and both have an enormous impact on well-being and daily functioning. Several prospective studies suggest that depression is a risk factor for cognitive decline $(1-3,6)$. In elucidating the association between depression and cognitive decline, it has been hypothesized that exposure to depression may be etiologically linked to a decline in memory functioning. However, the results of this study did not confirm this hypothesis. Furthermore, we examined whether exposure to depression symptoms was associated with a decline in information processing speed or global cognitive functioning. The results did not show any association between depression and global cognitive decline, whereas there was an association between chronic mild depression and chronic depression, and a decline in information processing speed. As the latter is predominantly affected by white matter lesions (26), these findings suggest that both depression and cognitive decline are the consequence of the same underlying subcortical pathology (27).

To our knowledge, this is the first study in which detailed information on the course of depression was available and used in analyses. On the base of repeated measurements within a period of three years, we distin- guished five depression course types which were different with respect to severity and duration of depression symptoms: non-depressed, remission, incident depression, chronic mild depression, and chronic depression. This highly variable course of depression between baseline and the last $\left(\mathrm{t}_{7}\right)$ measurement emphasizes the importance of access to repeated measurements of exposure to depressive symptoms in this type of study.

The present study showed one unexpected result. Persons who became depressed during the follow-up period had significant better scores on immediate recall than the non-depressed group. The delayed recall score was, as expected, the same as in the non-depressed group. There seems to be no theoretical basis for this finding. It is most probably an artifact as, after inspecting the raw scores, this group contained some persons who had relatively low scores on immediate recall at baseline measurement which, considering the size of this subsample $(\mathrm{N}=37)$, influences the mean immediate recall score. This low score may be the consequence of another condition which may precede depression. Further research in this incident depression group is necessary in order to clarify this finding.

\section{Depression and cognition}

To a certain extent, the association between depression and cognition is clear. Persons who are depressed may have (reversible) cognitive deficits as a consequence of motivational and attention problems. Furthermore, those who are becoming demented may become depressed as a psychological reaction to eroding cognitive capacities early in the course of dementia (4). However, some issues still need clarification. First, depression may arise as an early reaction to perceived cognitive decline years before dementia becomes clinically apparent (7). Support for this hy- 
pothesis is suggested in some studies which have investigated the association between depression and incident dementia $(6,28)$ or global cognitive decline $(2)$. Second, depression and cognitive decline may be a consequence of the same underlying pathology. It has been shown in brain magnetic resonance images that elderly depressed people have more frequent and more severe white matter and other subcortical abnormalities (12). Support for this hypothesis was obtained in our former study (8) and also in the present study. The third explanation for the association between depression and cognitive decline is that prolonged stress may have adverse (neurotoxic) effects on the brain, particularly the hippocampus, and thus on memory function. In younger patients with severe depression, former research on this hypothesis showed conflicting results. In our older population, we found no association between depression and decline in memory function.

\section{Study limitations}

Some limitations should be taken into account in the interpretation of our findings. First, selective non-response at baseline and loss to follow-up of people with severe depressive symptoms or cognitive problems is an inevitable problem in community-based research, and leads to underrepresentation of the more frail elderly. Although we tried to minimize loss to follow-up because of depression by including persons with at least three measurements, we may still have included relatively healthy persons. Second, unfortunately, at this moment our study lacks measures of cortisol and white matter pathology in the brain. Instead, we used depression symptoms as a measure of stress, and used cognitive tests which may represent specific underlying brain structures. As a consequence, we were only able to evaluate the indirect effect of depression on cognitive functioning. Further research with measures of cortisol and brain imaging techniques is necessary to examine these hypothesis more directly. Third, although we monitored depressive symptoms within three years quite well (29), no information was available on the history of depressive symptoms before baseline measurement. Further research is needed in order to examine this issue. Fourth, no adjustments were made for the use of anti-depressants. However, former research in this study population $(6,8)$ showed that very few persons had been treated for their depressive symptoms and that this did not influence the results. Fifth, a study in which stress level was induced by cortisol treatment showed that memory performance was decreased only by cortisol treatment conditions resembling moderate to high stress levels, not mild stress levels (30). Perhaps, the stress level of our subjects was not high enough to have this neurotoxic effect. Lastly, the memory test showed a learning effect after three years of followup. Although a parallel version of the memory test was used at three-year follow-up, the test procedure may have been remembered by respondents. This is a well-known problem when using memory tests in a longitudinal research design. However, persons with memory problems do not show this learning effect or, if they do show it, it is to a lesser extent. Nevertheless, our finding that depression is not associated with decline in memory performance may be attributable to this learning effect.

\section{CONCLUSIONS}

The results of the present study suggest that depression is not etiologically linked to decline in memory function in older persons. Furthermore, we found no evidence that depression is associated with global cognitive deterioration. Again, we found that chronic depression is associated with a decline in speed of information processing, supporting the hypothesis that both chronic depression and cognitive decline are the consequence of the same underlying subcortical pathology. Research with brain imaging techniques is recommended in further examining this hypothesis.

\section{ACKNOWLEDGEMENTS}

This study was funded by the Dutch Ministry of Health, Welfare and Sports.

\section{REFERENCES}

1. Dufouil C, Fuhrer R, Dartigues JF, Alperovitch A. Longitudinal analysis of the association between depressive symptomatology and cognitive deterioration. Am J Epidemiol 1996; 144: 634-41.

2. Paterniti S, Verdier-Taillefer MH, Dufouil C, Alperovitch A. Depressive symptoms and cognitive decline in elderly people. Longitudinal study. Br J Psychiatry 2002; 181: 406-10.

3. Henderson AS, Korten AE, Jacomb PA, et al. The course of depression in the elderly: a longitudinal community-based study in Australia. Psychol Med 1997; 27: 119-29.

4. Bassuk SS, Berkman LF, Wypij D. Depressive symptomatology and incident cognitive decline in an elderly community sample. Arch Gen Psychiatry 1998; 55: 1073-81.

5. Yaffe K, Blackwell T, Gore R, Sands L, Reus V, Browner WS. Depressive symptoms and cognitive decline in nondemented elderly women: a prospective study. Arch Gen Psychiatry 1999; 56: 425-30.

6. Geerlings MI, Schoevers RA, Beekman AT, et al. Depression and risk of cognitive decline and Alzheimer's disease. Results of two prospective community-based studies in the Netherlands. Br J Psychiatry 2000; 176: 568-75.

7. Jorm AF. Is depression a risk factor for dementia or cognitive decline? A review. Gerontology 2000; 46: 219-27.

8. Comijs HC, Jonker C, Beekman AT, Deeg DJ. The association between depressive symptoms and cognitive decline in community-dwelling elderly persons. Int J Geriatr Psychiatry 2001; 16: 361-7.

9. Sapolsky RM. Glucocorticoids and hippocampal atrophy in neuropsychiatric disorders. Arch Gen Psychiatry 2000; 57: 925-35.

10. Sapolsky RM. Why stress is bad for your brain. Science 1996; 273: 749-50.

11. Baddeley AD, Wilson BA, Watts FN. Handbook of memory disorders. Chichester, NY: Wiley, 1995.

12. Alexopoulos GS, Meyers BS, Young RC, Kakuma T, Silbersweig D, Charlson M. Clinically defined vascular depression. Am J Psychiatry 1997; 154: 562-5. 
13. Deeg DJH, Knipscheer CPM, van Tilburg W. Autonomy and wellbeing in the aging population: concepts and design of the Longitudinal Aging Study Amsterdam. Bunnik, The Netherlands: Netherland Institute for Gerontology, 1993.

14. Knipscheer CPM, de Jong-Gierveld J, van Tilburg TG. Living arrangements and social networks of older adults. Amsterdam: VU University Press, 1995.

15. Radloff LS. The CES-D scale: a self-report depression scale for research in the general population. Appl Psychol Measures 1977; 3: 385-401.

16. Geerlings SW, Beekman AT, Deeg DJ, van Tilburg W. Physical health and the onset and persistence of depression in older adults: an eight-wave prospective community-based study. Psychol Med 2000; 30: 369-80.

17. Berkman LF, Berkman CS, Kasl S, et al. Depressive symptoms in relation to physical health and functioning in the elderly. Am J Epidemiol 1986; 124: 372-88

18. Beekman AT, Deeg DJ, Van Limbeek J, Braam AW, De Vries MZ, van Tilburg W. Criterion validity of the Center for Epidemiologic Studies Depression scale (CES-D): results from a community-based sample of older subjects in The Netherlands. Psychol Med 1997; 27: 231-5.

19. Rey A. L'examen clinique en psychologie (Clinical examination in psychology). Paris: Presse Universitaire de France, 1964.

20. Savage RD. Alphabet Coding Task 15. Western Australia: Murdoch University, 1984.

21. Folstein MF, Folstein SE, McHugh PR. "Mini-mental state". A practical method for grading the cognitive state of patients for the clinician. J Psychiatr Res 1975; 12: 189-98.
22. Lezak MD. Neuropsychological assessment, 3rd ed. New York: Oxford University Press, 2002.

23. Luteijn F, van der Ploeg FAE. Groninger Intelligentie Test. Handleiding (Groninger Intelligence Test. Manual). Lisse, The Netherlands: Swets \& Zeitlinger, 1983.

24. Kriegsman DM, Penninx BW, van Eijk JT, Boeke AJ, Deeg DJ. Self-reports and general practitioner information on the presence of chronic diseases in community dwelling elderly. A study on the accuracy of patients' self-reports and on determinants of inaccuracy. J Clin Epidemiol 1996; 49: 1407-17.

25. Garretsen HFL. Probleemdrinken: prevalentiebepaling, beïnvloedende factoren en preventie-mogelijkheden. (Problem drinking: prevalence, determinants and prevention.). Lisse, The Netherlands: Swets \& Zeitlinger, 1983.

26. Breteler MM, van Swieten JC, Bots ML, et al. Cerebral white matter lesions, vascular risk factors, and cognitive function in a population-based study: the Rotterdam Study. Neurology 1994; 44 : 1246-52.

27. Salloway S, Malloy P, Kohn R, et al. MRI and neuropsychological differences in early- and late-life-onset geriatric depression. Neurology 1996; 46: 1567-74.

28. Devanand DP, Sano M, Tang MX, et al. Depressed mood and the incidence of Alzheimer's disease in the elderly living in the community. Arch Gen Psychiatry 1996; 53: 175-82.

29. Geerlings SW, Beekman AT, Deeg DJ, Twisk JW, van Tilburg W. Duration and severity of depression predict mortality in older adults in the community. Psychol Med 2002; 32: 609-18.

30. Newcomer JW, Selke G, Melson AK, et al. Decreased memory performance in healthy humans induced by stress-level cortisol treatment. Arch Gen Psychiatry 1999; 56: 527-33. 